\title{
Ocorrência, distribuição, danos e controle de pulgões do gênero Cinara em Pinus Spp. no Brasil
}

\author{
Susete do Rocio Chiarello Penteado \\ Rosita de FÁtima TRENTINI (IN MEMORIAN) \\ EDSON TADEU IEDE \\ WILSON REIS FILHO
}

\begin{abstract}
RESUMO
Pulgões do gênero Cinara foram registrados em plantios de Pinus spp., no Brasil, a partir de 1996, estando atualmente amplamente distribuídos pelos estados do Rio Grande do Sul, Santa Catarina, Paraná, São Paulo e Minas Gerais. Espécies originárias dos Estados Unidos e Canadá encontraram no Brasil condições ideais para seu desenvolvimento e dispersão, em função da ausência de inimigos naturais específicos, alimento disponível em abundância e pouca resistência ambiental. Estudos bioecológicos foram conduzidos pela Embrapa Florestas, juntamente com a UFPR, contando com o apoio do Funcema, visando à elaboração de uma estratégia de controle, baseada principalmente na utilização do controle biológico clássico.

Palavras Chave: afídeos, sintomas de ataque, controle biológico
\end{abstract}

\section{INTRODUÇÃO}

Os quase dois milhões de hectares de Pinus existentes no Brasil estão implantados, na sua grande maioria, em extensos monocultivos. Este fato, associado às precárias condições de manejo de muitos destes plantios, têm predisposto estas áreas ao ataque de diferentes espécies de insetos e doenças.

Nos últimos anos, com o crescente fluxo internacional de pessoas e vegetal, tem ocorrido a disseminação de um número cada vez maior de agentes patogênicos, que, muitas vezes, trazem prejuízos incalculáveis à economia de muitos países. Normalmente, quando uma espécie de inseto é introduzida em um país, ela ingressa livre dos agentes de controle natural existentes no país de origem, os quais são responsáveis pela manutenção da sua população em níveis toleráveis, sem provocar perdas econômicas. Entretanto, encontrando no novo 
habitat condições favoráveis ao seu desenvolvimento e alimento disponível em abundância, este inseto tornar-se-á uma praga e provocará danos à cultura, com consequências econômicas e até sociais. Como exemplo, podemos citar a introdução, adaptação e dispersão da vespa-da-madeira (Sirex noctilio) no Brasil (IEDE et al. 1988), cuja área atacada é de aproximadamente 300.000 ha, podendo provocar um prejuízo da ordem de US\$ 6,6 milhões, se medidas de controle não estivessem sendo adotadas.

Da mesma forma, foram registradas no Brasil, as espécies de afídeos, Cinara pinivora (IEDE et al, 1998) e C. atlantica (LAZZARI \& ZONTA-DECARVALHO, 2000), respectivamente, em 1996 e em 1998, atacando plantios de Pinus taeda e P. elliottii. Introduzidos acidentalmente em nosso país, estes afídeos, que são originárias dos Estados Unidos e Canadá, encontram-se amplamente distribuídas em plantios de Pinus spp.

Em função da capacidade dos afídeos em tornarem-se pragas, logo após a sua constatação no Brasil, a Embrapa Florestas, juntamente com o Departamento de Zoologia da Universidade Federal do Paraná e Funcema (Fundo Nacional de Controle à Vespa-da-Madeira), iniciaram, em 1997, um projeto de pesquisa para estudar os aspectos bioecológicos do inseto, visando subsidiar a definição de uma estratégia de controle, incluindo, principalmente, a introdução de inimigos naturais dos países de origem da praga.

\section{CARACTERÍSICAS DAS ESPÉCIES E HOSPEDEIROS}

Afídeos ou pulgões são pequenos insetos pertencentes à superfamília Aphidoidea, sendo a família Aphididae a mais comum, contendo cerca de 4.000 espécies presentes no mundo inteiro (DIXON, 1987). São exclusivamente fitófagos, causando danos diretos, devido à sucção da seiva e injeção de saliva tóxica (algumas espécies) e, algumas vezes, danos indiretos, ocasionados pela transmissão de viroses.

Algumas características fazem com que estes grupos de insetos possam tornar-se pragas de diferentes culturas, tais como:

- $\quad$ ALTA FECUNDIDADE;

Polimorfismo dos indivíduos, com a presença de formas ápteras e aladas, sendo que a maior parte da sua vida os afídeos são ápteros e deslocamse muito pouco nas plantas, tornando-se alados para a dispersão em condições adversas;

Forma de reprodução, podendo ser anholocíclicos, quando ocorre apenas a reprodução por partenogenia, geralmente em regiões tropicais e subtropicais e dando origem a fêmeas vivíparas e, em regiões temperadas, são holocíclicos, quando no final do outono e início do inverno ocorre a alternância 
da reprodução sexuada e partenogenética, dando origem a machos e fêmeas ovíparas (CARVER et al., 1991), as quais depositam os ovos de inverno.

Para a sua alimentação, os afídeos inserem o seu estilete na planta, até atingir o floema. Este é um processo demorado, que pode levar de 25 minutos a 24 horas. A seiva do floema é rica em açúcares e pobre em aminoácidos. Assim, ele necessita ingerir uma grande quantidade de seiva, para obter a quantidade de aminoácidos necessária à sua sobrevivência. Desta forma, ingere também uma grande quantidade de açúcares, o qual é eliminado na forma de "honeydew". Este "honeydew" é utilizado como alimento para muitas espécies de insetos e fungos.

Afídeos do gênero Cinara ocorrem em coníferas das famílias Pinaceae e Cupressaceae, distribuídos por várias regiões do mundo. São nativas da América do Norte, 150 espécies; 30 espécies são originárias da Europa e Mediterrâneo e 20 espécies do Extremo Oriente (EASTOP, 1972).

De acordo com EASTOP (1972), o gênero Cinara é considerado um grupo primitivo, devido às seguintes características: grande tamanho dos seus indivíduos (2 a $7 \mathrm{~mm}$ ), venação das asas completa, corpo muito pubescente, vestígios de um terceiro segmento tarsal, $4^{\circ}$ e $5^{\circ}$ segmentos do estilete bem definidos, olhos compostos, ausência de plantas hospedeiras alternativas e associação com coníferas.

Na América do Sul, o gênero Cinara foi detectado pela primeira vez, em Cupressus lusitanica, na Colômbia, em 1973. A espécie foi identificada inicialmente como C. fresai e mais tarde, como C. cupressi (MILLS, 1990).

Cinara pinivora (WILSON, 1919) (Lachninae, Cinarini), é uma espécie nativa da América do Norte (leste dos Estados Unidos e Canadá) (BLACKMAN \& EASTOP 1984; VOEGTLIN \& BRIDGES 1988). Foi introduzida acidentalmente na Austrália, Argentina, Uruguai e Brasil (PENTEADO et al., 2000). O registro no Brasil foi feito por IEDE et al. (1998), no município de Lages, SC e Cambará do Sul, RS, nos meses de junho e julho de 1996, respectivamente, atacando plantios de $P$. elliottii e $P$. taeda. Posteriormente, esta espécie foi detectada em diferentes municípios dos estados do Rio Grande do Sul, Santa Catarina e Paraná.

Como hospedeiros de $C$. pinivora são citados na literatura as seguintes espécies: Pinus banksiana, $P$. clausa, $P$. elliottii, $P$. pungens, $P$. resinosa, $P$. rigida, $P$. sylvestris, $P$. taeda e $P$. virginiana (VOEGTLIN \& BRIDGES, 1988).

Cinara atlantica foi registrada no Brasil em 1998 (LAZZARI \& ZONTA-DE-CARVALHO, 2000), tendo sido verificada, inicialmente, em plantios de $P$. taeda e $P$. elliottii, no município de Lages, SC, juntamente com colônias de C. pinivora. De acordo com JOHNSON \& LION (1976), esta é a espécie mais importante na região sul dos Estados Unidos, atacando plantios de 
Pinus spp. A sua presença foi constatada também na Jamaica e em Cuba (BLACKMAN \& EASTOP, 1984).

No Brasil C. atlantica já foi registrada em diferentes municípios dos estados do Rio Grande do Sul, Santa Catarina, Paraná, São Paulo e Minas Gerais, sendo uma espécie que se desenvolve em temperaturas mais altas que C. pinivora.

Os hospedeiros de $C$. atlantica no Brasil, são as espécies, $P$. taeda, $P$. elliottii, $P$. patula e espécies de pinus tropicais. VOEGTLIN \& BRIDGES (1988) citam como hospedeiros as espécies, $P$. clausa, $P$. echinata, $P$. elliottii, $P$. glabra, $P$. pungens, $P$. resinosa, $P$. rigida, $P$. serotina, $P$. strobus, $P$. sylvestris, $P$. taeda e $P$. virginiana.

Além das duas espécies de Cinara citadas, foram também constatadas no Brasil as espécies $C$. fresai, $C$. piniformosana, C. maritima e $C$. thujafilina, sem, no entanto, provocarem danos.

\section{DANOS E SINTOMAS DE ATAQUE}

De acordo com CIESLA (1991), todas as espécies de Cinara alimentam-se de ramos, brotos e ocasionalmente raízes de coníferas das famílias Cupressaceae e Pinaceae.

KIDD (1988) comenta que apesar da existirem inúmeras espécies de afídeos da família Lachninae atacando folhosas, a principal preocupação está naquelas espécies que atacam coníferas.

PEPPER \& TISSOT (1973), verificaram que o pico populacional de $C$. pinivora ocorre entre o final do outono e durante o inverno, sendo que as colônias praticamente desaparecem nos meses mais quentes. No Brasil, a ocorrência de $C$. pinivora também se dá entre o outono e inverno, sendo que em dias com temperaturas altas eles desaparecem, abrigando-se dentro de ninhos de formigas associadas e nas raízes. C. atlantica é uma espécie que tolera temperaturas mais altas, ocorrendo juntamente com $C$. pinivora, durante o outono e inverno e também é encontrada durante a primavera e verão.

Os afídeos são facilmente transportados para novas áreas, através de mudas, sendo que algumas espécies foram introduzidas em áreas onde plantações de coníferas haviam sido estabelecidas e tornaram-se pragas. De acordo com KIDD (1988), quando ocorre a introdução tanto da planta hospedeira como da espécie de afideo associada, podem ocorrer problemas muito sérios. Este mesmo autor verificou um acréscimo de mais de dez vezes na população de $C$. pinea de um ano para outro, quando os predadores estavam ausentes. Entretanto, acrescentou que a magnitude do crescimento populacional depende da qualidade do hospedeiro.

Tanto os adultos como as ninfas dos afídeos alimentam-se da seiva do floema da planta hospedeira. Ataques intensos podem provocar a queda de ramos e a morte da planta (CIESLA, 1991). Segundo FURNISS \& CAROLIN (1977), a maioria das espécies de Cinara alimentam-se em colônias, localizadas 
geralmente nos brotos ou ramos e em alguns casos em raízes. Muitas espécies atacam apenas um gênero de planta e outras são específicas a uma única espécie.

Os danos podem ser causados tanto pela extração dos nutrientes, como pela injeção de toxinas contidas nas secreções salivares, ou ainda pela fumagina, causada por fungos que se desenvolvem sobre o "honeydew" excretado pelos pulgões. Esta fumagina reduz a área fotossintética, dificultando os processos de respiração e transpiração da planta, interferindo no seu desenvolvimento. Observa-se ainda a associação com formigas, as quais alimentam-se do "honeydew" e protegem os pulgões de seus inimigos naturais. Um outro aspecto observado foi que, as formigas, ao se alimentarem, realizam uma "limpeza" do local, pois sem elas, a colônia fica envolta por múltiplas gotículas do "honeydew", o que dificulta o desenvolvimento e locomoção dos pulgões. BURNS (1973) observou que a presença de formigas aumentou a sobrevivência do pulgão Toumeyella liriodendri, de 8,2 para 46,8\%, provavelmente interferindo na ação de parasitóides e predadores.

KIDD (1988) verificou que como a maioria dos afídeos alimenta-se através da extração da seiva do floema, isto pode provocar a queda das acículas, a redução ou distúrbio de crescimento, assim como, reduzir a resistência da planta ao ataque de outros insetos ou patógenos. A ação contínua do inseto, em altas infestações que venham a se repetir ao longo dos anos, pode causar a morte das plantas.

De acordo com PEPPER \& TISSOT (1973), as densas colônias de $C$. pinivora distribuem-se praticamente sobre toda a planta: caule, ramos e acículas. Na Flórida e Carolina do Sul, foi observada a presença das colônias na ponta dos ramos; muitas vezes eles foram encontrados dispersos ao longo de ramos mortos e, algumas vezes, sob acúmulo de acículas mortas que ficam presas nos ramos das árvores.

As árvores atacadas por $C$. pinivora podem apresentar os seguintes sintomas: clorose, deformação e queda prematura das acículas; redução no desenvolvimento da planta; entortamento do fuste e superbrotação devido à destruição do broto apical (PENTEADO et al., 2000). KIDD (1988) observou algumas modificações morfológicas próximas aos locais de alimentação, como o afilamento irregular do tronco, dilatação nodal e rompimento da casca, todos eles contribuindo para a redução do valor econômico da madeira.

FOX \& GRIFFITH (1977) observaram uma redução significativa no crescimento em diâmetro e altura de $P$. taeda de um a dois anos de idade, infestada por C. atlantica, na Carolina do Sul.

De acordo com KIDD (1984), os afídeos apresentam um crescimento, sobrevivência e fecundidade ótimos, quando atacam plantas jovens, em pleno crescimento, ou partes jovens de plantas adultas, sendo que o oposto também é verdadeiro. 
Perdas econômicas devido ao ataque de $C$. cupressi em ciprestes e cedros, no Malawi, foram estimadas por ODERA (1991), em cerca de US\$ 2.4 milhões, no final de 1990. Segundo AUSTARA (1970), existe uma estreita relação entre os danos causados pelo inseto e o crescimento da planta tendo observado que um desfolhamento de $100 \%$ em Pinus patula resultou em uma redução de crescimento de $50 \%$.

\section{CONTROLE}

Em função dos riscos ambientais e custos associados ao controle químico de pragas em ecossistemas florestais, o controle de Cinara spp., no Brasil, deverá basear-se, principalmente em métodos biológicos, mecânicos e silviculturais, utilizados de forma integrada, para comporem um "Programa de Manejo Integrado de Pulgões em Pinus" (MIP), que deverá envolver, essencialmente: (1) monitoramento, através da utilização de armadilhas e inspeções terrestres; (2) controle silvicultural, pela utilização de sementes e mudas de boa qualidade e procedência garantida, utilização de espécies alternativas e plantios multiclonais, escolha de sítios para o plantio, realização de tratos silviculturais emergenciais, manutenção da cobertura vegetal, visando proporcionar um ambiente favorável ao desenvolvimento de fungo entomopatogênicos e abrigo a inimigos naturais, entre outras; (3) resistência de plantas e (4) controle químico, o qual seria recomendado apenas para prevenir explosões populacionais em plantações de alto valor comercial, como bancos clonais, pomares de semente. Entretanto esta alternativa necessita ser investigada, pois não existem testes de eficiência de produtos e nem registro para uso em Pinus, no Brasil.

Como parte do MIP, o controle biológico desta praga é um dos aspectos mais importantes. Como os afídeos passam grande parte do tempo, alimentando-se imóveis e em grupos ou colônias, eles são facilmente encontrados e atacados por seus inimigos naturais.

De acordo com ROTHERAY (1989), um dos mais importantes grupos que visitam as colônias de pulgões, são os predadores, os quais podem ser divididos em:

- Predadores obrigatórios, ou específicos: alimentam-se unicamente de afídeos. Pertencem a este grupo, as joaninhas (Coleoptera: Coccinellidae), moscas da família Sirphidae, Cecidomyiidae, crisopídeos (Neuroptera: Chrysopidae), hemípteros da família Anthocoridae, algumas vespas solitárias e outras espécies de moscas.

- Facultativos ou polífagos: alimentam-se de uma gama de insetos. Neste grupo estão incluídos muitas espécies de besouros, vespas sociais, pássaros, etc.

SEGUNDO MILLS (1990), devido à falta de especificidade dos predadores, eles tendem a ter um menor impacto sobre uma determinada 
espécie, dentro de um largo espectro de presas que atacam. Em muitos casos, os predadores estão ligados mais a hábitos específicos, do que a hospedeiros específicos. Por exemplo, na Europa, algumas espécies de predadores estão associadas a florestas de coníferas.

No Brasil, tem sido registrados com frequiência a presença dos predadores das famílias Coccinellidae (joaninhas), Syrphidae (moscas) e Chrysopidae (bicho-lixeiro).

Levantamentos realizados no Malawi por CHILIMA (1991), mostraram que um grande número de predadores, principalmente larvas de sirfídeos e coccinelídeos estavam alimentando-se sobre os afídeos, mas eles não foram efetivos para reduzir a população dos mesmos.

De acordo com FRANK \& FOLKS (1991), no complexo de inimigos naturais de afídeos, os parasitóides são a parte mais importante, principalmente devido à sua especificidade. Estes mesmos autores afirmam que por razões biológicas e econômicas, as pragas que mantêm populações moderadamente altas de forma constante, são melhores para serem controladas biologicamente, do que aquelas que são escassas por um determinado período e, repentinamente, ocorrem surtos.

HAGVAR \& HAFSCANG, (1991) acrescentam que os afídeos da subfamília Lachninae têm como seus mais importantes parasitóides, espécies da família Braconidae (Himenóptera). O gênero Pauesia ataca todos os afídeos da subfamília Lachninae (MILLS, 1990).

Após a constatação de Cinara cronartii em plantios de Pinus spp. da África do Sul, uma espécie do gênero Pauesia foi introduzida, do sudeste dos Estados Unidos e controlou com sucesso a praga (KFIR et al., 1985). Posteriormente a espécie foi identificada como P. bicolor (MILLS, 1990). As espécies $P$. cupressobii, e $P$. junipterorum têm sido registradas parasitando Cinara juniperi, um afídeo que ataca Juniperus communis. Estes dois parasitóides são considerados específicos ao gênero Cinara, os quais se alimentam sobre plantas da família Cupressaceae. Outro parasitóide, Aphidus sp. foi registrado em C. cupressi, na Alemanha (MILLS, 1990).

RIO MORA \& VOEGTLIN (1988) registraram um importante parasitóide no México, a vespa Aphididius sp. (Himenóptera: Aphydiidae), a qual controlou a população de pulgões do gênero Cinara de forma eficiente naquele país.

Assim, a Embrapa Florestas, juntamente com a UFPR e Funcema elaboraram um projeto definindo uma estratégia de controle para as espécies de Cinara que estão atacando Pinus spp. no Brasil. Esta estratégia envolve a identificação e avaliação de predadores de $C$. atlantica e $C$. pinivora detectados no Brasil, além da introdução de parasitóides dos países de origem da praga. De acordo com MILLS (1990), os parasitóides apresentam um grande potencial para uso no controle desta praga. 
O programa de controle biológico a ser implementado no Brasil, baseado na utilização do controle biológico clássico, deverá selecionar inimigo natural específicos no local de origem da praga. Em função de não provocar desequilíbrio ao ecossistema florestal, acredita-se que este método, uma vez implementado, fornecerá um controle efetivo da praga, como ocorreu em outros países, com pragas similares (Pinus e Cinara spp.).

\section{CONCLUSÃO}

A preocupação com a ocorrência de novas pragas em plantios de Pinus spp. no Brasil tem crescido substancialmente. Isto se deve ao fato de, nos últimos anos, terem sido registrados ataques, tanto de espécies introduzidas (vespa-da-madeira e afídeos), como a adaptação de espécies nativas (macacoprego e ratão). Fatores como a ausência de inimigos naturais específicos, abundância de alimento disponível e a simplificação do ambiente, têm favorecido o aumento populacional destas pragas e, conseqüentemente, ocasionando prejuízos ao produtor.

Assim, para favorecer o equilíbrio do ecossistema florestal, além da utilização de inimigos naturais, o controle das espécies $C$. pinivora e $C$. atlantica, no Brasil, deverá envolver outros métodos de controle, que deverão ser utilizados de forma integrada, pelo desenvolvimento e adoção de um Programa de Manejo Integrado das Cinara spp. em plantios de Pinus spp.

\section{REFERÊNCIAS BIBLIOGRÁFICAS}

AUSTARA, O. 1970. The effects of artificial defoliation on the growth of Pinus patula in East Africa. E. Afr.Agri. For. Journal 36:114-118.

BLACKMAN, R. L.; EASTOP, V. F. 1984. Aphids on the world's crops: Na identification and information guide. Wiley and Sons. New York.

BURNS, D.P. 1973. The foraging and tending behavior of Dolichoderus taschenbergi (Hymenoptera: Formicidae). The Canadian-Entomologist. 105: 1. p. 97-104.

CARVER, M., GROSS, G. F. Woodward, T. E. 1991. Hemiptera, p. 429-509. In: (CSIRO ed.) The Insects of Australia - A textbook for students and research workers, Melbourne University Press.

CHILIMA, C. Z. 1991. The Status and Development of Conifer Aphid Damage in Malawi. In: Exotic aphids pests of conifers - A crisis in African forestry. Muguga, Kenya, June 1991. Proceedings Kenya Forestry Research Institute/Fao. Kenia. p. $64-67$. 
CIESLA, W. M. The cypress aphid, Cinara cupressi (Buckton) in Africa. In: Exotic aphids pests of conifers - A crisis in African forestry. Muguga, Kenya, June 1991. Proceedings Kenya Forestry Research Institute/Fao. Kenia. p. $33-47$.

DIXON, A. F. G. 1987. Aphid reproductive tactics. In Population structure, genetics and taxonomy of aphids and Thysanoptera. (eds). J. Holman; J. Pelikan; A.F.G.Dixon and L. Weismann (The Hague: SPB Academic Publishing) p. 3-18.

EASTOP, V.F., 1972. A taxonomic review of the species of Cinara Curtis occuring in Britain (Hemiptera: Aphididae) Bull. British Museum (Natural History). Entomology, 27:101-186.

FOX, R. C., GRIFFITH, K. H. 1977. Pine seedling growth loss caused by cinaran aplhids in South Carolina. J. Georgia Entomol. Soc. 12: 29-34.

FURNISS, R.L. \& CAROLIN, V.M. 1977. Western forest insects, USDA Forest Service, Misc. Pub, 1339, 654 p.

HAGVAR, E.B. \& HAFSCANG, T. 1991. Aphid parasitoids (Hymenoptera, Aphidiidae): biology, host selection and use in biological control. Biocontrol News and Information, 12:13-41.

IEDE, E.T.; PENTEADO, S.R.C.; BISOL, J.C. Ocorrência de ataque de siricídios (Hymenoptera:Siricidae) em Pinus taeda L. no estado do Rio Grande do Sul. In: Congresso Florestal do Paraná, 2. Anais. Curitiba: Instituto Florestal do Paraná, 1988. p. 2.

IEDE, E.T.; LAZZARI, S.M.N.; PENTEADO, S.R.C.; ZONTA-DE CARVALHO, R.C. \& RODRIGUES-TRENTINI, R.F. 1998. Ocorrência de Cinara pinivora (Homóptera: Aphididae, Lachninae) em reflorestamentos de Pinus spp. No sul do Brasil. Congresso Brasileiro de Zoologia. Recife, PE. Anais. p. 141.

JOHNSON, W. T. \& LYON, H. H. 1976. Aphids on conifers. Insects that feed on trees and shurbs-An Illustrated Practical guide. Cornell University Press. Ithaca, New York. 464p. 68-69p.

KIDD, N.A.C. 1988. The large pine aphid on Scots pine in Britain. In: Dynamics of Forest Insect Populations. A.A. Berryman ed., p. 111-128.

KIDD, N.A.C. \& TOZER, D.J. 1984. Host plant and crowding effects in the induction of alatae in the large pine aphid, Cinara pinea, Entomol. Exp. Appl. 35:37-42.

KFIR, R.; KIRSTEN, F. \& VAN RENSBURG, N.J. 1985. Pauesia sp. (Hymenoptera: Aphidiidae), a parasite introduced into South Africa for biological control of the balck pine aphid Cinara cronartii (Homoptera: Aphididae). Environmental Entomology 14: 597-601.

LAZZARI, S.M.N.; ZONTA-DE CARVALHO, R.C. 2000. Aphids (Homoptera: Aphididae: Lachninae: Cinarini) on Pinus spp. and 
Cupressus sp. in Southern Brazil. In: International Congress of Entomology, XXI. 2000. Foz do Iguaçu, PR. Anais. p. 493.

MILLS, N.J. 1990. Biological control of forest aphid pests in Africa. Bull. Entomol. Res., 80: 31-36.

ODERA, J.A. 1991. Some oportunities for managing aphids of woftwood plantations in Malawi. Assistance to Forestry Sector Malawi MLW/86/020. FAO, Rome, $135 \mathrm{p}$.

PENTEADO, S.R.C; TRENTINI, R.F.; IEDE, E.T.; REIS FILHO, W. 2000. Pulgão do Pinus: nova praga florestal. Série Técnica do IPEF. v.13, n.33. p. $97-102$.

PEPER, J. O.; TISSOT, A. N. 1973. Pine feeding Species of Cinara in the Eastern U. S. (Homoptera: Aphididade). Fla. Agr. Expt. Sta. Mono. Series. 3: 1-140.

RIO MORA, A. A. del; VOEGTLIN, D. 1988. Algumas observaciones sobre afídeos de importância forestal en el Campo Experimental Forestal "Barranca de Cupatitzio", Uruapan, Michoacan. Ciencia Forestal, México, V. 13, n. 64, p. $75-88$.

ROTHERAY, G. E. 1989. Aphid predators. Naturalists' Handbooks, 11. England. Richmond Publishing Co. Ltd. 77 p.

VOEGTHIN, D.A. \& BRIDGES, C.A. 1988. Catalog of the Cinara species of North America (Homoptera:Aphididae). Illinois Natural History Survey. Special Publication 8, 55 pp. 